\title{
Influences of Fault on the Stability of Surrounding Rocks in Roadways of Mines
}

\author{
Zhongsi Dou ${ }^{1, *}$, Jiwen $\mathrm{Wu}^{2}$, Yimeng Wang ${ }^{3}$ and Jinhe Gao ${ }^{1}$

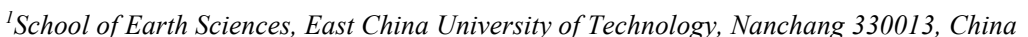 \\ ${ }^{2}$ School of Earth and Environment, Anhui University of Science \& Technology, Huainan 232001, China \\ ${ }^{3}$ School of Science and Engineering, University of Dundee, Dundee, U.K.
}

Received 18 July 2019; Accepted 27 December 2019

\begin{abstract}
Faults destroy the continuity and integrity of rock strata and change the transfer law of geostress near them. The deformation mechanism of surrounding rocks in a floor roadway of mines is difficult to analyze due to the existence of faults. In this study, a $-590 \mathrm{~m}$ horizontal surface roadway of Luling Mine in China was used as the study area to investigate the influences of fault on geostress transmission and determine the effects in controlling the deformation of surrounding rocks in a floor roadway of mines. Some measuring points of surrounding rock deformation were set in the horizontal surface at $20 \mathrm{~m}$ below the floor and three roadways (Roadways 1, 2, and 3) at $35 \mathrm{~m}$ below the floor to analyze the transfer law of mining-induced stress and stress changes and the displacement failure of surrounding rocks through similar material simulation experiment and fiber Bragg grating testing technology. A numerical simulation model was constructed on FLAC $^{3 \mathrm{D}}$ to verify the stress and plastic failures of surrounding rocks. Results demonstrate that the pressure relief and stress concentration in the gob approach the fault, and a stress turning point occurs at the fault with the advancement of the working face. Mining-induced stress runs through the fault, and a stress concentration zone with a certain size is formed at the footwall and hanging wall of the fault. The surrounding rock stress in Roadway 3 changes the most, followed by those in Roadways 2 and 1 when the relative distances from the working face to the different roadways are the same. The three roadways develop different degrees of deformation failure, which are manifested in the order of Roadway $3>$ Roadway $2>$ Roadway 1 when the working face runs through the fault. This finding demonstrates that faults can substantially control the transfer of mining-induced stress at the floor that reduces the stability of roadways. This study provides a real and accurate technological reference to the surrounding rock support in roadways of mines.
\end{abstract}

Keywords: Fault, Mining-induced stress, Roadway, Similarity simulation, Numerical simulation

\section{Introduction}

Many roadways are the lifeline of underground production systems. The deformation failure of roadways can easily cause roof caving, wall caving, and heaving floor and may induce coal and gas outburst, water inrush from the seam floor, and other disasters, thereby seriously threatening mine production safety [1-2]. After the mining of coal seams, the state of in situ stress field distribution changes, and a new stress field is produced, thereby affecting the surrounding rocks in underground roadways to different extents. The evolutionary laws of mining-induced stress under different geological conditions and the deformation mechanism of surrounding rocks in roadways should be effectively analyzed to provide scientific reference for the support and layout of roadways.

Many scholars have investigated the deformation failure mechanism of surrounding rocks in roadways. Geostress is believed to be the motive power of deformation failure in roadways. The surrounding rock stress in roadways exceeding the strength of surrounding rocks is the main cause of deformation failure in roadways. Therefore, two important and basic factors, namely, geostress and strength of surrounding rocks, are used to analyze the deformation

*E-mail address: hnzyjsxydzs@163.com ISSN: $1791-2377 @ 2019$ School of Science, IHU. All rights reserved. doi:10.25103/jestr.126.19 mechanism of surrounding rocks in roadways. They are influenced by multiple factors, including mining technology, working face size, geology, and construction conditions [35]. Investigation of stress evolution at the stope floor and roadway deformation are the key contents of studies on mining-induced stress field and the important prerequisites to reveal the deformation of surrounding rocks in the stope floor. With the refining classification of rock mechanics since the middle of the 20th century, some advancement have been achieved in investigating the mechanism of roadway deformation, including elasticity and elastoplastic analysis results of surrounding rocks of roadways, theoretically solving the elastic plane problem of surrounding rocks, and stability analysis of surrounding rocks in modern block mechanics [6]. Many studies have been conducted on the mechanism of stress-induced deformation failure of different roadways (e.g., coal and rock roadways) in mines and have achieved considerable results [7-9]. Research methods have been developed using the original elasticity and elastoplasticity methods in terms of rheology, damage, dilation, and fracture. Some assisted software has been presented with the rapid development of computer science to effectively examine the deformation mechanism of roadways. In addition to fault and fracture zones, sections with unstable surrounding rocks and high occurrence of accidents in roadways are common unfavorable geological phenomena during underground 
mining. Many associated studies have focused on the stress distribution pattern near the fault zone, supporting technique of roadway in the fracture zone of fault [10-11], fault activation law, and induced impact rock pressure [12-14]. Some scholars have conducted theoretical analysis to adjust the parameters using numerical simulation software [15-16]. Other scholars have collected and analyzed data using advanced monitoring technologies to set underground measuring points [17-18]. However, numerical simulation analysis cannot completely and objectively reflect the actual complicated geological conditions in underground environments, and underground measurement is infeasible because of its high cost. These issues cause great technological challenges in investigating the influences of geologic structure of fault on the deformation of roadways.

In this study, a roadway model with boundary fault structures and three floors was constructed through similar simulation. Experimental data were verified through numerical simulation to effectively analyze the deformation mechanism of roadways. The research conclusions can provide effective parameters for the reasonable layout and support of roadways.

\section{State-of-the-art}

Many studies have investigated the influences of fault on mining-induced stress transfer and stability of roadways. Islam et al. [19] explored the stress characteristics and deformation surrounding faults in the conveyor band roadway of Balapuria Mine (Bangladesh) through numerical simulation using a boundary element method. They found that the redistribution of mining-induced stress causes significant deformation in and around the two faults, and high stress concentrates near the ends of the two faults. The vertical tensile stress on the upper end of Fault $\mathrm{Fb}$ is relatively high. High stress concentrated at the ends of $\mathrm{Fb}$ and Fb1 implied that the trend of block damage occurs near the fault zone. Wang et al. [20] analyzed the deformation failure mechanism of normal fault roadways with small falls. Their results showed that the asymmetric mining-induced stress field near the fault is the main cause of roadway deformation failure. Stress concentrated in the footwall of fault causes evident shear slip in the key positions of the roadway. On the basis of studies on convergence and deformation of roadways, Piotr et al. [21] found that the vertical convergence of single fault is $30 \%$ higher than that of roadways without geological disturbance, and the vertical convergence of roadway in the fault zone is four times higher than that of roadways without disturbance. They concluded that roadways have crucial impacts on the deformation failure of floor roadways. Lu et al. [22] deduced the analytic expression of hydraulic pressure of water inrush from the seam floor under the influences of fault. The influencing laws of the distance between open-off cut on the working face and fault zone, dip angle of fault, advancing direction of working face, and coefficient of horizontal pressure on hydraulic pressure of water inrush from the seam floor were analyzed. Moreover, the influences of fault on stress transfer in the stope floor were disclosed.

Liu et al. constructed a microseismic monitoring system to effectively monitor the fault activity and applied it to an alldimensional tracking and monitoring of the working face with high water inrush risk under practical conditions. The results demonstrated that mining activity could significantly influence the fault activity. The fault activity is enhanced, and the risk of water inrush increases accordingly when the working face approaches the fault. The fault activity stabilizes at the end of excavation activity. $\mathrm{Xu}$ et al. [23] used the common IV-level surrounding rocks, which are soft and easy to be broken in mountainous tunnels, as the reference object and investigated the progressive failure of surrounding rocks and stress change characteristics during the construction of crossing-fault tunnels through a laboratory model test. They found that tunnel excavation leads to the redistribution of surrounding rock stress, and loosening and plastic zones are formed on the surrounding rocks. The surrounding rocks would collapse and form an arch when the increase in surrounding rock stress caused by excavation exceeds the ultimate strength of rock mass. The rock stress on the hanging wall and footwall on the fault contact surface is discontinuous because of fault separation, especially when the overlying load is high. The maximum contact stress is observed at the intersection between the fault and pressure-bearing arch. Ding et al. [24] evaluated the failure of supporting structure in Shiziyuan Tunnel that is across the fault by conducting experimental studies on geostress and surrounding rock strength. They found significant asymmetry in the surrounding rock stresses between the left and right sides of the tunnel and between the internal supporting force and surrounding rock deformation when the soft rock tunnel with high geostress region runs through the fault. This asymmetry is related to the uneven stresses on the tunnel structure caused by complicated tectonic stresses. Wang et al. [25] assessed the stress concentration at different end positions of the fault in the south mining area of Qidong Mine and analyzed the asymmetric deformation characteristics of the roof, waist, and floor of roadways close to one side of the fault. They concluded that the fault structural surface results in changes of stress field close to the fault, and stress concentration regions in the middle of fault surface are formed on the upper and lower ends along the relative slippage. Thus, the roadways close to the fault surface are influenced by eccentric loads, resulting in their asymmetric deformation. Dai et al. [26] analyzed the transfer law and difference of loads from the basic roof of gob of the working face to the two sides of the fault. Their finding showed that the load transfer coefficient on fault is high the pressure on the coal pillar of fault at the hanging wall is small, and the pressure on coals at the footwall high when the hanging wall is mined first. On the contrary, the load transfer coefficient of fault is related to the angle of fault when the footwall is mined first. The overlying loads in the gob of the footwall can be transferred to the hanging wall when the fault angle is large to ensure small pressure on the coal pillar of fault at the footwall and high pressure of coals at the hanging wall. The overlying loads at the footwall cannot be transferred to the hanging wall of fault when the fault angle is small. Therefore, the pressure of coal pillar at the fault of the footwall is relatively large, but the pressure of coal pillar at the hanging wall is relatively small.

Zhai et al. [27] constructed a similar material model of fault using the rock formation at the two sides of $F$ tension fault in Longdong Coal Mine as the prototype. They applied this model to track and monitor the mining-induced stress at the coal seam near the fault zone and the variation law of rock stress at the two sides of the fault zone. The results demonstrated that the leading bracing stress at $30 \mathrm{~m}$ below the floor of the coal seam exhibits strong reaction with the advancing of the working faces. The concentrated stress of floor reaches the maximum $(127.64 \mathrm{kPa})$, and the stress 
concentration coefficient is 2.8 when the coal pillar width decreases to $30 \mathrm{~m}$. The loads obviously reduce from the point near the fault zone in the deep floor of the coal seam accompanied with the significantly different changes in stress at the two sides of the fault zone when the coal pillar width decreases to $20 \mathrm{~m}$. The influences of fault zone on stress transfer are demonstrated. The hanging wall and footwall show different mining characteristics that easily "activate" the fault.

These studies have mainly investigated the stress characteristics close to the fault through field investigation, basic data analysis, numerical simulation, and similar material simulation by focusing on a specific engineering geological background. They have revealed the characteristics of mining-induced stress field and the stability law of surrounding rocks in roadways under the control of fault. The stress distribution characteristics at the two sides of the fault zone were analyzed through numerical simulation and theoretical analysis [19-22]. Although these studies are supported by strong theoretical frameworks, they ignore the complexity of geological structures. The stress characteristics close to the fault were investigated through field measurement or original engineering geological data of mines [23-26]. Although the authenticity of data is significantly improved, the sampling and detection cost are high. Thus, these studies have largely depended on the original data. The influences of fault on the evolution of mining-induced stress were investigated using a similar simulation model [27]. The abovementioned studies [19-27] have focused on a specific geological condition, and their conclusions lack verification.

Therefore, a similar simulation experiment on surrounding rock stress in roadways below the $-590 \mathrm{~m}$ working face of Luling Mine in China was conducted using the fiber Bragg grating (FBG) technology. The innovations of this study are presented as follows. On the one hand, the model included three roadways for stress analysis under the existence or nonexistence of fault control (Roadways 1 and 2) and on the hanging wall and footwall of the fault (Roadways 2 and 3). This model can significantly decrease the error of experimental results caused by defects (e.g., construction and mixing ratio of raw materials) of the similar simulation model. On the other hand, the plastic failure of surrounding rocks in floor roadways was analyzed through numerical simulation to verify the accuracy of conclusions.

The remainder of this study is organized as follows. Section 3 presents the engineering geological model extracted from the mine data using FBG and constructs a similar material model. Stress monitoring points are horizontally paved at the stope floor. The monitoring points are set near the surrounding rocks in three roadways, and a simulation analysis on the deformation mechanism of surrounding rocks of roadways is conducted. Section 4 analyzes the influences of fault on stress evolution in floor roadways and the deformation of underlying roadways on the basis of the simulations results of similar material test. The controlling effect of fault over the surrounding rocks in roadways is analyzed through FLAC $^{3 \mathrm{D}}$ numerical simulation. The results present a good fit to the similar simulation results. Section 5 provides the conclusions.

\section{Methodology}

3.1 Technical background of original mine engineering
The thickness and horizontal elevation of the primary mining seam of Luling Mine were 10.58 and $590 \mathrm{~m}$, respectively, on the basis of field investigation data. The fault near the coal seam is a normal fault, and the surrounding rocks are relatively cracked (Fig. 1).

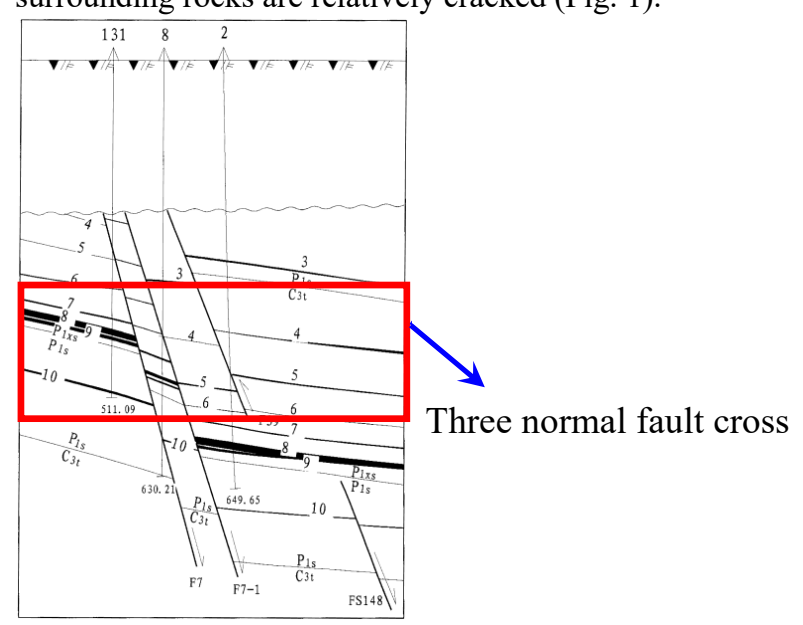

Fig. 1. Fault near the coal seam

The roadway with straight wall and semicircular arch is a soft-rock roadway with a vertical distance of $35 \mathrm{~m}$ to the primary mining seam and surrounding rocks that are mainly composed of siltstone and mudstone. The height of the straight wall and the radius of the upper semicircular arch are 2 and $3 \mathrm{~m}$, respectively. Coal seam mining is delayed with the advancing of roadway. This mine provides a drilling column of the rock strata (Fig. 2).

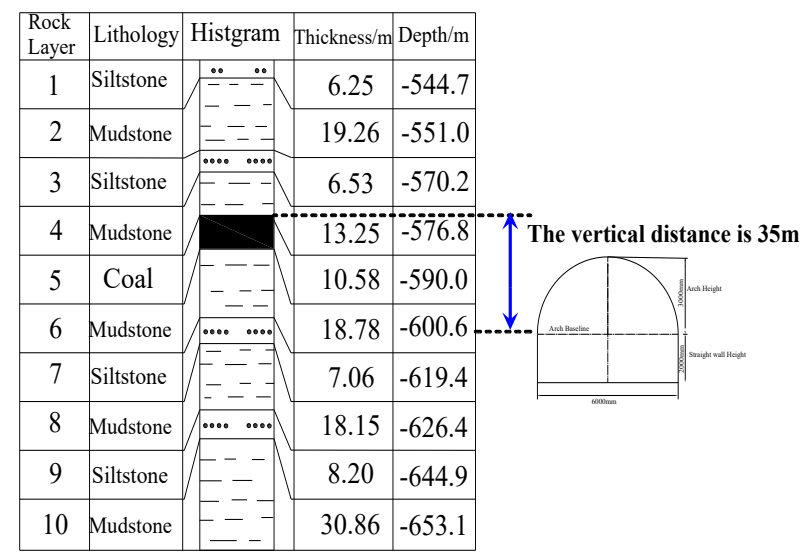

Fig. 2. Drilling column of the wall

In situ rock samples collected from the field are shown in Fig. 3. Tags 1, 2, and 3 are siltstone, mudstone, and raw coals, respectively.

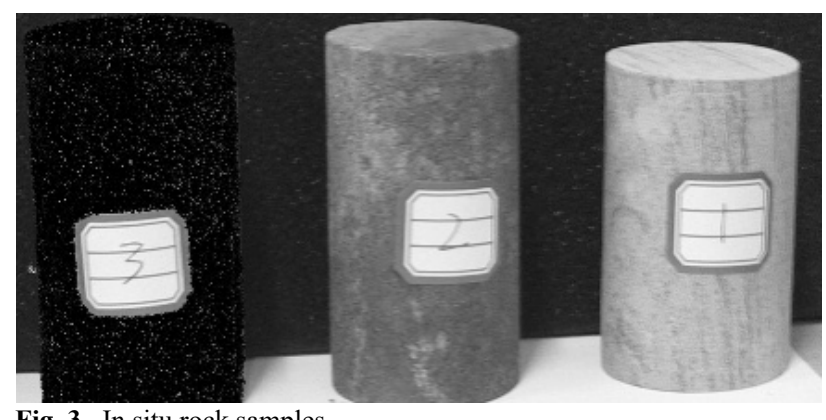

Fig. 3. In situ rock samples

Mechanical parameters of rocks were obtained through and MTS uniaxial compression test (Table 1). 
Table 1. Strength test of rock samples at the testing point

\begin{tabular}{c|c|c|c|c}
\hline Lithology & $\begin{array}{c}\text { Elasticity } \\
\text { modulus } \\
\text { /GPa }\end{array}$ & $\begin{array}{c}\text { Tensile } \\
\text { strength } \\
\text { /GPa }\end{array}$ & $\begin{array}{c}\text { Compressive } \\
\text { strength } \\
\text { /MPa }\end{array}$ & $\begin{array}{c}\text { Shear } \\
\text { strength } \\
\text { /MPa }\end{array}$ \\
\hline Siltstone & 8.06 & 3.15 & 18.15 & 7.56 \\
Mudstone & 6.19 & 2.43 & 12.36 & 3.84 \\
Raw coal & 3.56 & 1.12 & 5.78 & 1.47 \\
\hline
\end{tabular}

\subsection{Similar simulation test}

\subsubsection{Construction of an experimental model}

The geometric size of the model was $300 \mathrm{~cm}$ (length) $\times 30$ $\mathrm{cm}$ (width) $\times 120 \mathrm{~cm}$ (height).

The model preparation is presented as follows:

1) Sand, lime, gypsum, and water were weighted based on the mixing ratio of different layers and stirred in a blender.

2) The samples were paved layer-by-layer from the bottom to top, and the thickness of each layer was strictly controlled using a scale plate. Each layer was leveled using a level gauge.

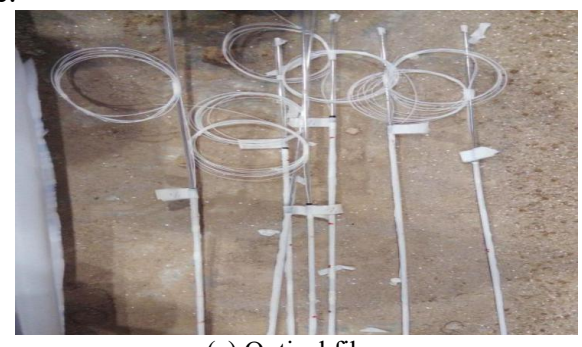

(a) Optical fiber

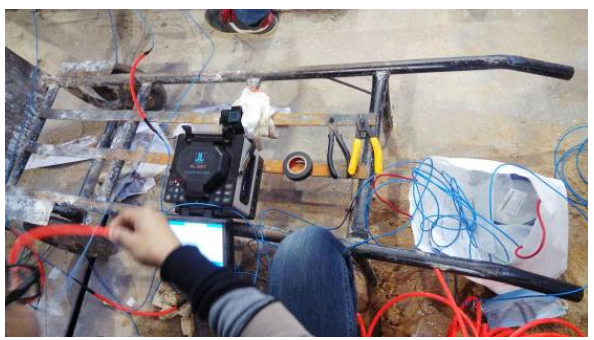

(c) Welding

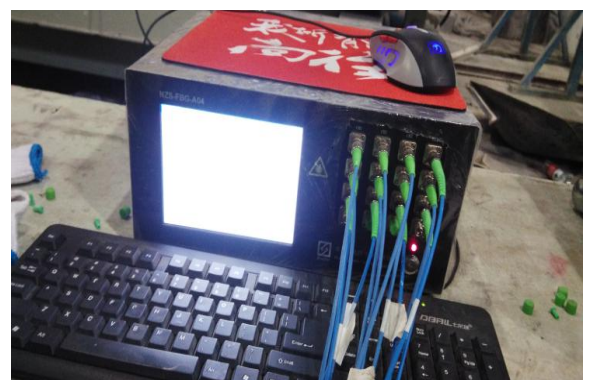

(e) Connection of the analyzer

Fig. 4. Preparation of the similar simulation model of fault structure

\subsubsection{Selection of monitoring method}

Real-time tracking and monitoring of strain on the roof and floor were conducted using FBG technology during the recovery of coal seam to discuss the influences of fault on the stress transfer in the stope and evolution of surrounding rock stress in the roadway. The reflected central wavelength is related to the grating period and effective refractive index of the fiber core. Therefore, changes in temperature and strain surrounding the FBG sensor can induce changes in central wavelength $(\lambda B)$ of the Bragg reflected light, which can be expressed as:
3) All layers were compacted individually. $P_{e}$ During compaction, attention was given to the protection of optical fibers. After reaching the compaction effect, the fiber optic lead interface was monitored using a fusion splicer to ensure the integrity of each layer of optical fiber.

4) After the completion of the model construction, all fiber optic lead interfaces were monitored, and the module was disassembled after one week. The model reached the design strength after two weeks under natural ventilation conditions.

5) Balancing weights were placed at the top $48 \mathrm{~h}$ before model excavation.

6) A coordinatometer was pasted on the left and lower boundaries of the model, and a layer of gypsum was coated on the model surface. Then, the model was dried, and mark point was pasted. Black ink was coated on the external side for convenient observation. The model preparation is shown in Fig. 4, and the finished model is presented in Fig. 5.

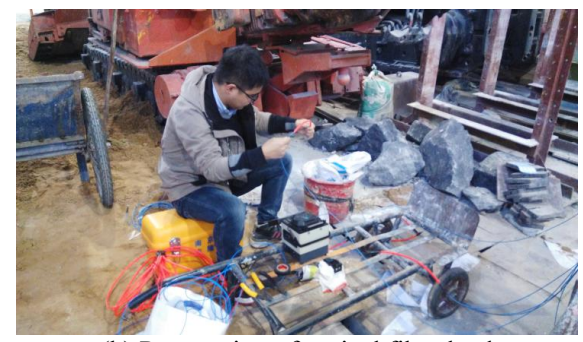

(b) Preparation of optical fiber lead

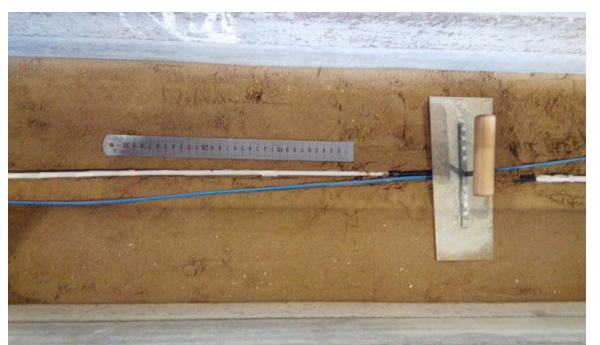

(d) Embedding of optical fiber

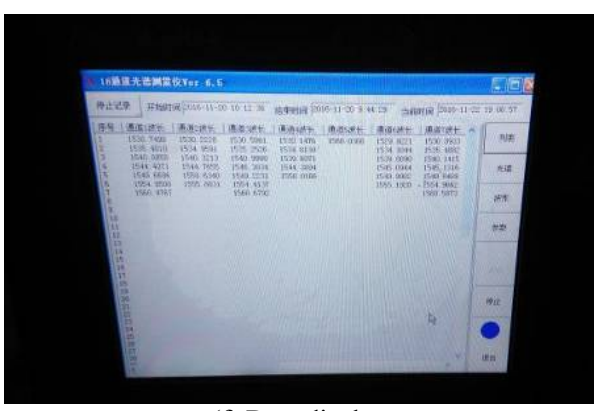

(f) Data display

$\frac{\Delta \lambda}{\lambda_{B}}=\left(1-P_{e}\right) \varepsilon+(\alpha+\zeta) \Delta T$

where $\Delta \lambda$ is the change in Bragg central wavelength, $\Delta T$ is the temperature change, $\varepsilon$ is the axial strain, $\zeta$ is the thermooptical coefficient of the optical fiber, $\alpha$ is the thermal expansion coefficient of the optical fiber, and $P_{e}$ is the effective photoelastic coefficient. The numerical value of $P_{e}$ is approximately 0.22 .

The physical simulation monitoring device was a 16channel FBG analyzer provided by Suzhou Nanzhi Sensing Technology Co., Ltd. The technological indicators of the device are listed in Table 2. 
Table 2. Technological indicators of FBG analyzer

\begin{tabular}{c|c|c|c}
\hline Type of indicator & Value & Type of indicator & Value \\
\hline Number of channels & 8 & Type of optical interface & FC/APC \\
Wavelength range $(\mathrm{nm})$ & $1529-1569$ & Maximum FBG number in each channel & 30 \\
Wavelength resolution $(\mathrm{pm})$ & 1 & Communication interface & Ethernet $(\mathrm{RJ} 45)$ \\
Repeatability $(\mathrm{pm})$ & \pm 3 & Power supply & $\mathrm{AC} 220 \mathrm{~V} / 50 \mathrm{~Hz}$ \\
Demodulation rate $(\mathrm{Hz})$ & $\geq 1$ & Power consumption $(\mathrm{W})$ & $<15 \mathrm{~W}$ \\
Dynamic range $(\mathrm{dB})$ & 35 & Working temperature $\left({ }^{\circ} \mathrm{C}\right)$ & $0{ }^{\circ} \mathrm{C}$ to $45^{\circ} \mathrm{C}$ \\
\hline
\end{tabular}

Stress calculation: the difference between the testing and initial wavelengths is multiplied by 845 to obtain the microstrain at the measuring point (the elastomer can be considered without failure when the strain is lower than 1,000 . The strain is multiplied with elasticity modulus to obtain the stress value [28].

\subsubsection{Distribution of strain measuring points}

Model monitoring positions: 10 measuring points were set at $20 \mathrm{~cm}$ below the coal seam and were recorded as $1,2 \ldots 10$.

The horizontal distance of measuring points was $30 \mathrm{~cm}$. Another 12 measuring points were set on the surrounding rocks of the roadway at $35 \mathrm{~cm}$ below the coal seam. The measuring points on the surrounding rocks in Roadway 1 were denoted as Roadways 1-1, 1-2, 1-3, and 1-4. The measuring points on the surrounding rocks in Roadway 2 were denoted as Roadways 2-1, 2-2, 2-3, and 2-4. The measuring points on the surrounding rocks in Roadway 3 were denoted as Roadways 3-1, 3-2, 3-3, and 3-4. See Fig. 6 for detail.

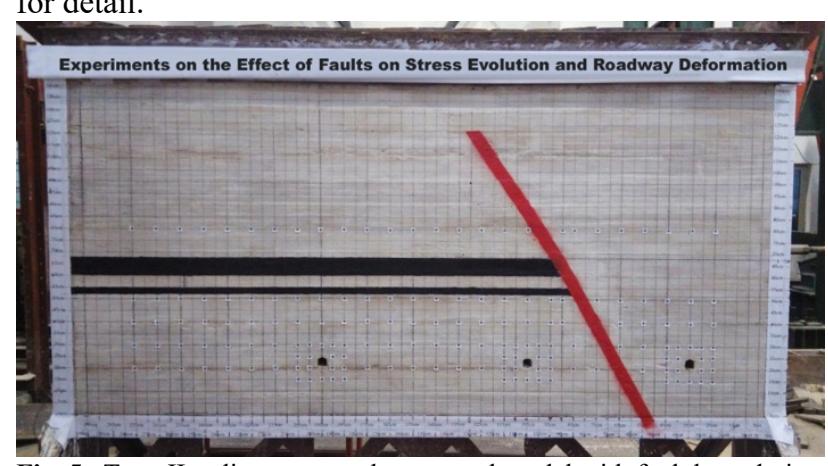

Fig. 5. Type II sedimentary rock structural model with fault boundaries

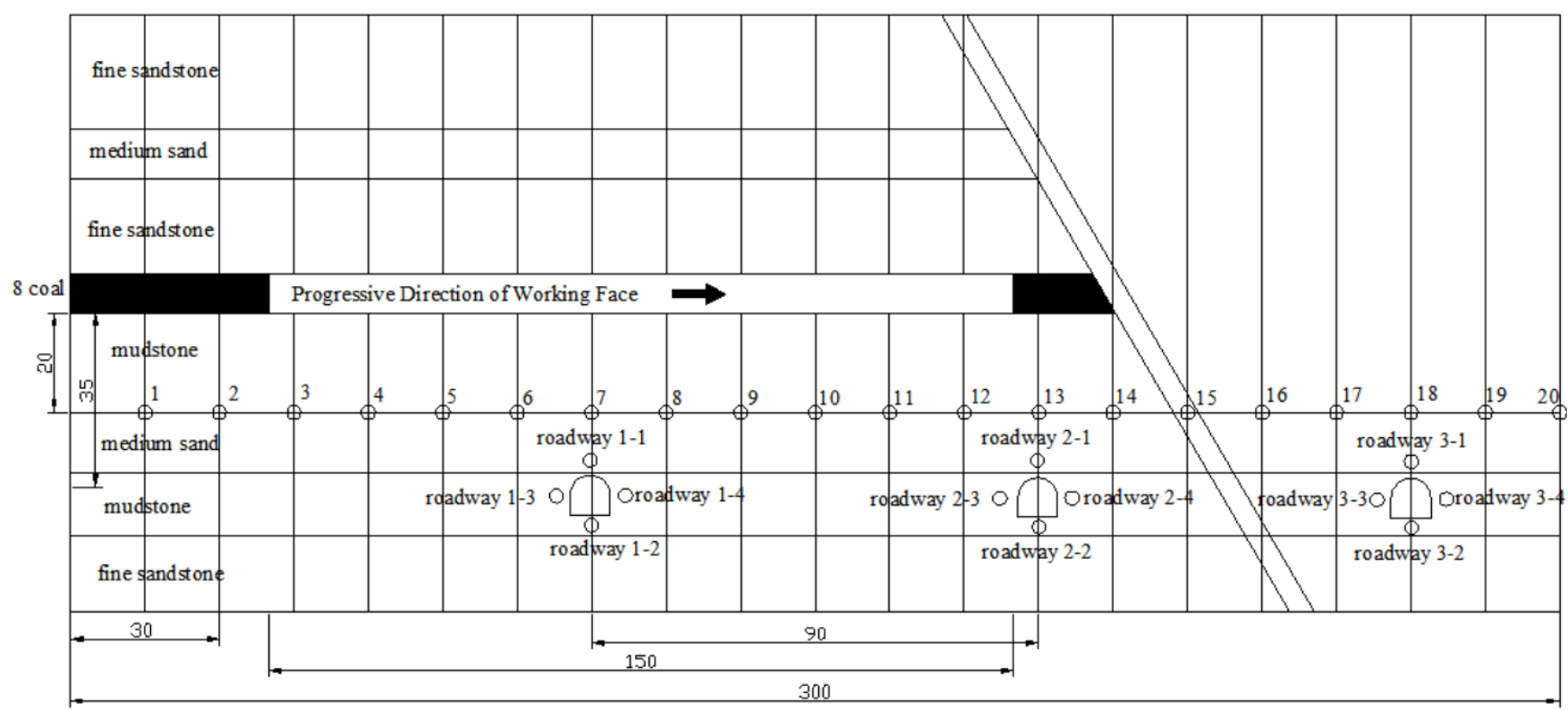

Fig. 6. Sketch map of the stress measuring points of the optical fiber

\section{Results Analysis and $\Delta$ iscussion}

Surrounding rock stress is at a relatively equilibrium state before coal seam mining. After mining, the surrounding rock stress in the gob will be redistributed, and the stress on the gob floor is released. The stress concentrates on the gob roof and transfers to the surrounding areas. The stress distribution presents a certain law, that is the stress concentration is formed within a certain range surrounding the gob, and pressure relief forms in the floor at a certain range. The stress concentration and pressure relief weaken with the face can be divided into four parts, namely, (1) leading bracing pressure zone $(10-40 \mathrm{~cm}$ in front of the working face): this region is significantly influenced by mining causing a sharp growth of stresses and the occurrence of peak support pressure. The peak continues to increase, and the maximum stress $(16.3 \mathrm{MPa})$ is achieved at $130 \mathrm{~cm}$ with increase in distance. The stress on the floor is continuously adjusted and changed with the gradual advancing of the working face. The adjusted stress distribution is the motive power for plastic failure and deformation displacement of the surrounding rocks in roadways. The mining-induced stress can influence the spatial transfer in the floor with the existence of faults thereby resulting in different deformation failure effects to floor roadways.

The curves are drawn from the testing results of measuring points during the mining of coal seams at $20 \mathrm{~cm}$ below the floor (Fig. 7). The floor in front of the working the advancing of the working face. (2) Slight change region of stress (40-80 cm in front of the working face): this region is influenced by mining activity, and stress slightly increases. (3) Stress region of primary rock (80-200 cm in front of the working face): the floor is not influenced by mining-induced stress, and the stress of primary rock is maintained. The 
stress value is $10.2 \mathrm{MPa}$. (4) Secondary growth region of stresses (distance $>200 \mathrm{~cm}$ ): stress rapidly increases from $2.4 \mathrm{MPa}$ to $12 \mathrm{MPa}$. This region is the fault zone at $200 \mathrm{~cm}$, indicating that mining-induced stress runs through the fault during mining along the fault trend. Thus, the stresses are relatively concentrated on the hanging wall and footwall and affect the scope within $80 \mathrm{~cm}$. Such phenomenon is unfavorable to the stability of surrounding rocks in a floor roadway.

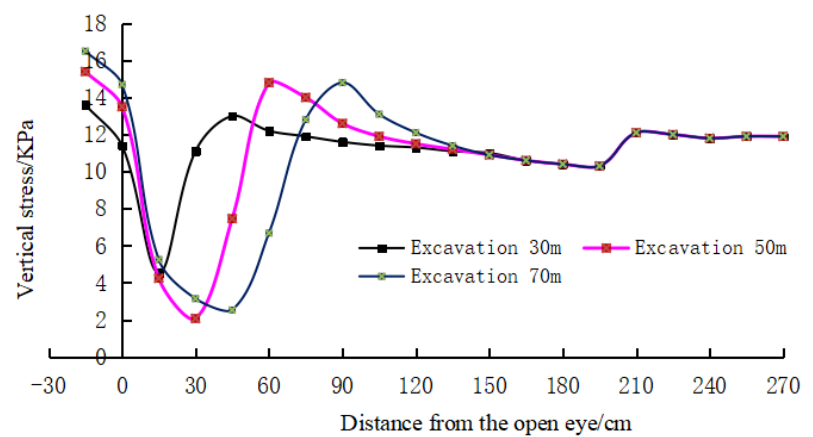

(a) Fault is far from the working face

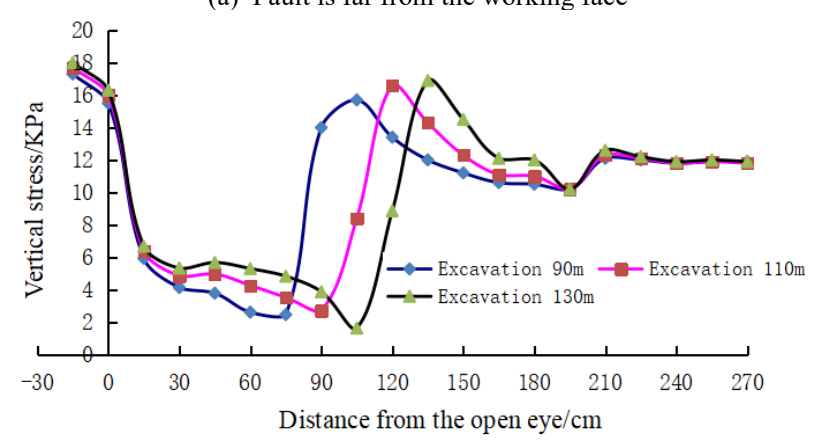

(b) Fault is near the working face

Fig. 7. Monitoring results at different depths of seam floors

The stress changes of measuring points in Roadways 1 and 2 were analyzed to investigate the control effect of fault over mining-induced stress on the surrounding rocks of the floor and roadway. The relative advancing distance was fixed in the analysis to ensure the comparability of research results. In other words, the results on the measuring points with the same relative distance to the head of working face were chosen for comparison. The results of this study were consistent with the variation laws. The stress on the floor was supercharged and relieved with the continuous advancing of the working face. Significant differences were found in the amplitude. The results are shown in Fig. 8.

As shown in Fig. 8(a), the growth of roof stress in the two roadways reaches the peak $(0.8 \mathrm{kPa})$, and pressure relief subsequently begins when Roadways $1-1$ and $2-1$ are at 80 $\mathrm{m}$ of the advancing distance of the working face. Pressure relief is $1.4 \mathrm{kPa}$ when Roadway $1-1$ is at $100 \mathrm{~m}$ of the advancing distance, and pressure relief at Roadway 2-1 reaches $3 \mathrm{kPa}$. As shown in Fig. 8(b), the growth of stress on the right side of the two roadways reaches the maximum (3.1 $\mathrm{kPa}$ ) when Roadways 1-4 and 2-4 are at $70 \mathrm{~m}$ of the advancing distances, and pressure relief subsequently begins. Pressure relief is $3.4 \mathrm{kPa}$ when Roadway $1-1$ is at $100 \mathrm{~m}$ of the advancing distance, and pressure relief at Roadway 2-1 reaches $7.6 \mathrm{kPa}$. These findings reflect that the same law is obtained from the strain analysis between Roadways 1-2 and 2-2 and between Roadways 1-3 and 2-3 using the same method. Thus, the same law is obtained, indicating that the stress on the measuring points of surrounding rocks of roadways near the fault zone is significantly higher than that of the surrounding rock stress in roadways far from the fault zone. Hence, the roadways near the fault zone are easy to be deformed.

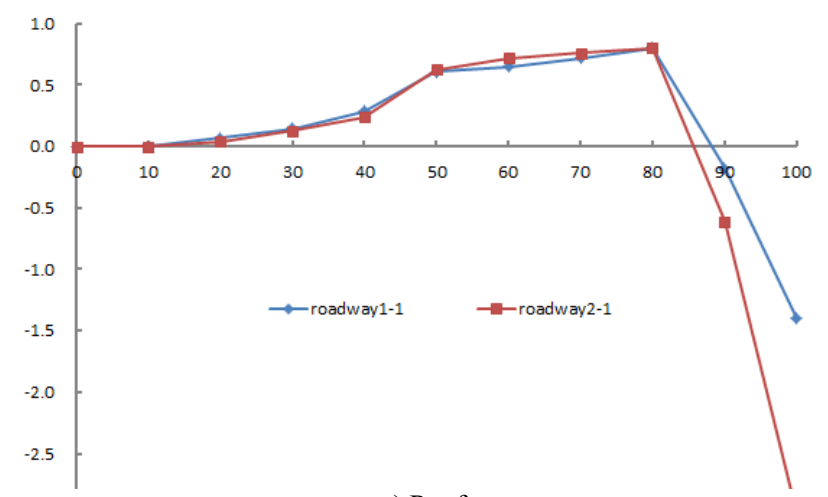

a ) Roof

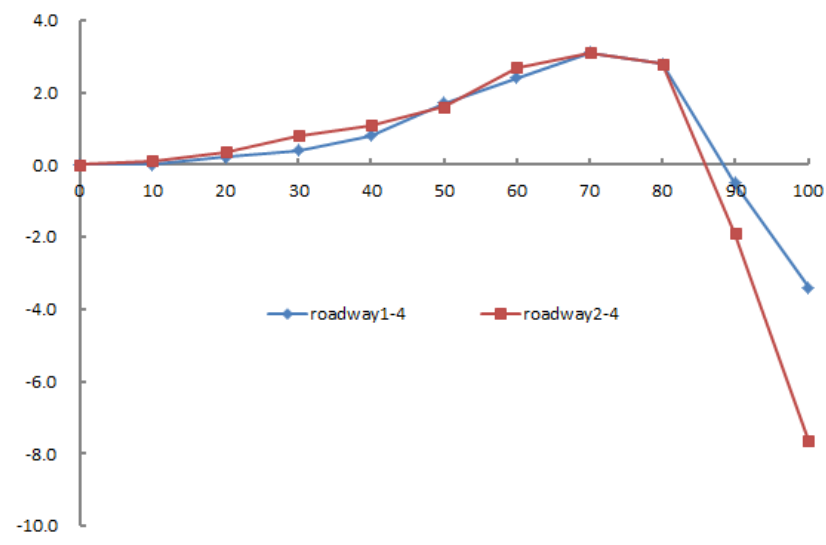

(b) Right side

Fig. 8. Comparison of mining-induced stresses under equal distances to the head of working face

The stresses at the measuring points in Roadways 2 and 3 were analyzed to discuss the different control effects of fault on the evolution of mining-induced stress of surrounding rocks in the two sides of roadways. The advancing distance was fixed to ensure the comparability of research results. The analysis results are shown in Fig. 9. As shown in Fig. 9(a), the maximum stress peak is achieved when the measuring points on the left side of the roadway is at $70 \mathrm{~m}$ of the advancing distance. The stress peak at Roadway 3-1 reaches 7.7, which is approximately $0.7 \mathrm{kPa}$ higher than that at Roadway 2-1. This finding implies that although roadways in different walls of the fault have different distances to the fault, they are significantly influenced by stress. At the mining along the fault trend, the stress on Roadway 2 is smaller than that on Roadway 3. This finding conforms to the results in Section 4.1.

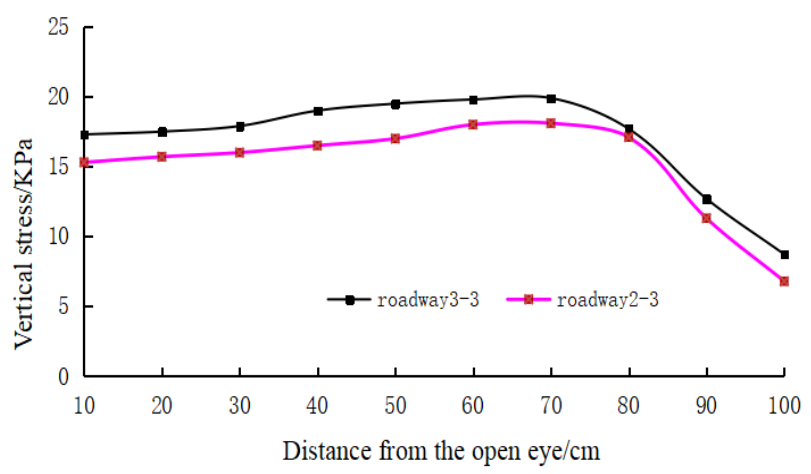

(a) Left side 


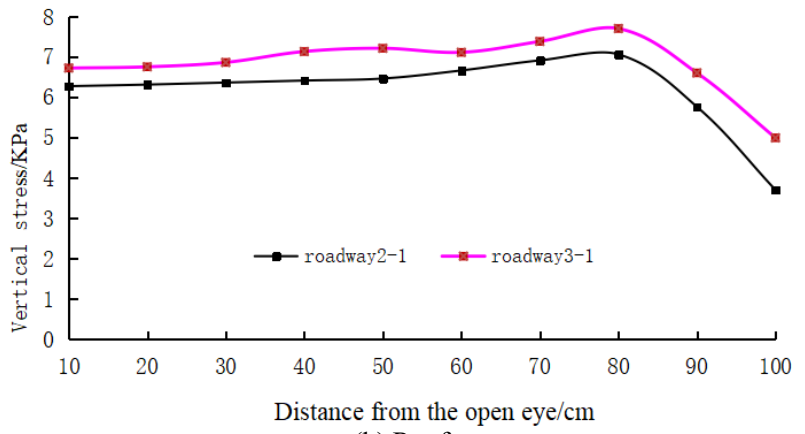

(b) Roof

Fig. 9. Comparison of mining-induced stress under equal distance to the head of working face

Three roadways were observed and analyzed when the working face advanced forward by $130 \mathrm{~m}$ to analyze the crack propagation law of floor roadways. The results are shown in Fig. 10.

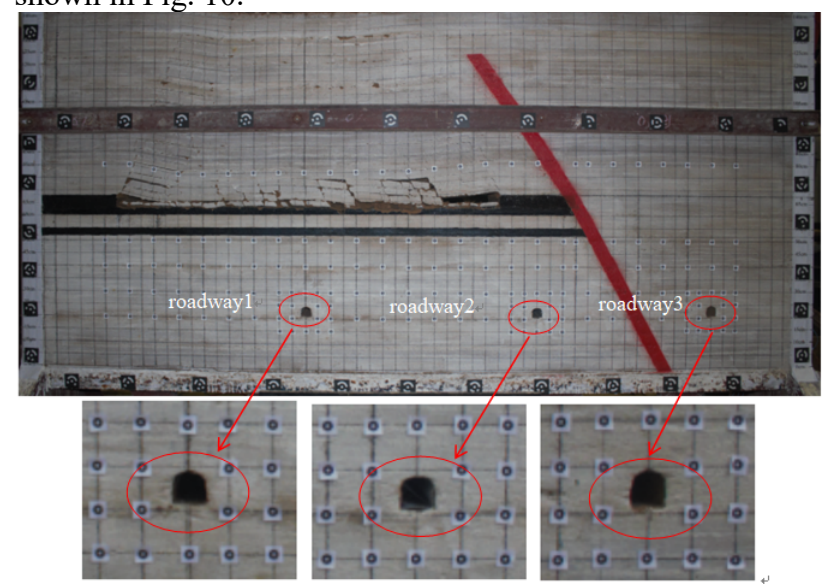

Fig. 10. Model at $130 \mathrm{~m}$ of advancing distance

Roadways 1, 2, and 3 were enlarged for displacement analysis at different measuring points. The results showed that the deformation of Roadway 1 is the lowest, whereas the deformation of Roadway 3 is the highest. A fault is found in front of Roadway 2, resulting in high-pressure relief on the gob floor and accelerated tensile failure of roadways. Given that mining-induced stress runs through the fault zone, a stress concentration zone is formed on the hanging wall and footwall. Therefore, the deformation of Roadway 3 is higher than that of Roadway 2.

A three-dimensional numerical simulation model was constructed on FLAC $^{3 \mathrm{D}}$ to verify the controlling effects of the above similar simulated fault on mining-induced stress (Fig.13). This model was $350 \mathrm{~m}$ long along the $\mathrm{X}$ direction, $250 \mathrm{~m}$ wide along the $\mathrm{Y}$ direction, and $120 \mathrm{~m}$ high along the $\mathrm{Z}$ direction. The meshing density of the three roadways was increased. A total of 103,800 grids and 110,422 nodes were found in the model. The dip angle of the fault was set to $60^{\circ}$. The boundary conditions of the model are introduced as follows. Full constraint was applied at the bottom, and a free boundary condition was used at the top. The remaining four sides were fixed along the $\mathrm{X}$ and $\mathrm{Y}$ directions.

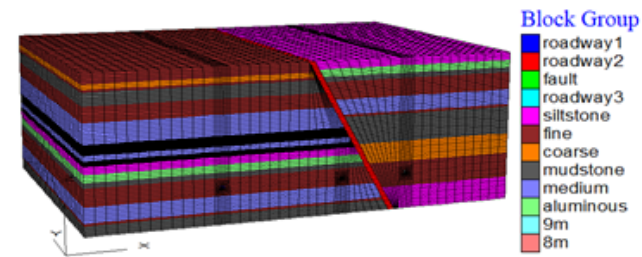

Fig. 11. 3D numerical simulation model

This calculation model can reflect the essence, constitutive relation, and failure criteria of research problems and the principle of physical mechanical state of rock materials. An integrally structured floor model and a floor model with fault boundary conditions were constructed. The two models used the Mohr-Coulomb plastic constitutive model and Mohr-Coulomb yielding criteria, which can be expressed as follows:

$$
f_{s}=\sigma_{1}-\frac{\sigma_{3}(1+\sin \varphi)}{1-\sin \varphi}+2 c \sqrt{\frac{1+\sin \varphi}{1-\sin \varphi}}
$$

$f_{t}=\sigma_{3}-\sigma_{t}$

where $\sigma_{1}$ and $\sigma_{3}$ are the maximum and minimum principal stresses (MPa), respectively, $c$ is the cohesion of rock mass $(\mathrm{MPa}), \varphi$ is the internal friction angle of rock $\left(^{\circ}\right)$, and $\sigma_{t}$ is the tensile strength of rock mass (MPa). The rock mass develops shearing failure when $f_{s}=0$ whereas it develops tensile failure when $f_{t}=0$.

The selection of mechanical parameters of the model is a key step in numerical simulation. An actual rock mass covers various forms of structural surfaces, such as joint, plane of unconformity, and soft intercalation. Therefore, the physical mechanical indexes of rock mass significantly differ from those of rock mass in the laboratory test. The simulation results may produce large errors when the laboratory test results are directly used as the simulation reference. Therefore, a specific method should be used to correct the physical mechanical indexes of rock masses. Many indexes, including elastic wave testing method, core drilling method, and statistical method of structural surface, can be used to represent the integrity of rock masses worldwide. Wave velocity testing can avoid the disturbances from drilling technology and reflect the integrity of rock masses. The mechanical parameters of rock mass used the physical mechanical indexes in the laboratory core drilling test of Luling Coal Mine. These parameters were obtained from the integrity coefficient through the wave velocity test. The mechanical parameters of rock mass in the simulation are listed in Table 3.

Table 3. Mechanical parameters of the numerical simulation model

\begin{tabular}{|c|c|c|c|c|c|c|}
\hline Lithology & $\begin{array}{l}\text { Bulk modulus } \\
\text { /GPa }\end{array}$ & $\begin{array}{c}\text { Shearing } \\
\text { modulus /GPa }\end{array}$ & $\begin{array}{l}\text { Density } \\
/ \mathrm{g} / \mathrm{cm}^{3}\end{array}$ & $\begin{array}{c}\text { Internal cohesion } \\
/ \mathrm{MPa}\end{array}$ & $\begin{array}{c}\text { Internal friction } \\
\text { angle } \\
/ 0\end{array}$ & $\begin{array}{c}\text { Tensile strength } \\
\text { /MPa }\end{array}$ \\
\hline Coal 8 & 0.09 & 0.08 & 1.38 & 1.25 & 32 & 0.25 \\
\hline Coal 9 & 0.09 & 0.08 & 1.38 & 1.25 & 32 & 0.25 \\
\hline Mudstone & 1.19 & 1.26 & 2.38 & 2.00 & 30 & 1.50 \\
\hline $\begin{array}{l}\text { Aluminous } \\
\text { mudstone }\end{array}$ & 1.29 & 1.36 & 2.48 & 2.10 & 31 & 1.60 \\
\hline Siltstone & 2.58 & 1.59 & 2.46 & 2.80 & 33 & 2.30 \\
\hline Fine sandstone & 1.54 & 1.88 & 2.54 & 3.00 & 35 & 2.40 \\
\hline
\end{tabular}




\begin{tabular}{c|l|l|l|l|l|l|l} 
Medium & 2.82 & 2.2 & 2.62 & 1.88 & 35 & 3.10 \\
sandstone & 3.61 & 2.5 & 2.89 & 1.98 & 35 & 3.20 \\
Coarse sandstone & 0.05 & 0.05 & 1.08 & 0.25 & 28 & 0.15 \\
Fault zone &
\end{tabular}

After advancing into the roadway, the maximum principal stress and displacement characteristics of surrounding rocks in roadways before mining of working faces are shown in Fig. 12.

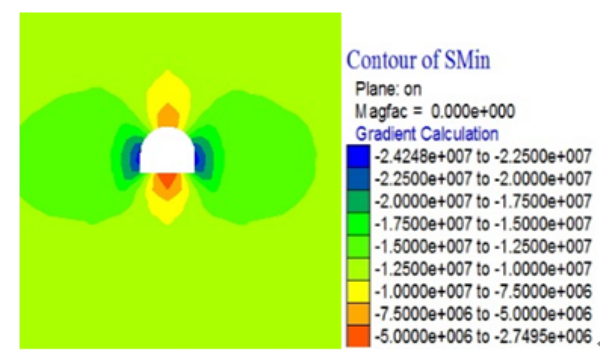

(a) Roadway 1

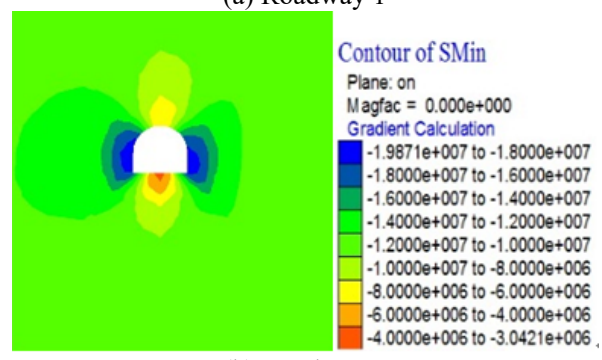

(b) Roadway 2

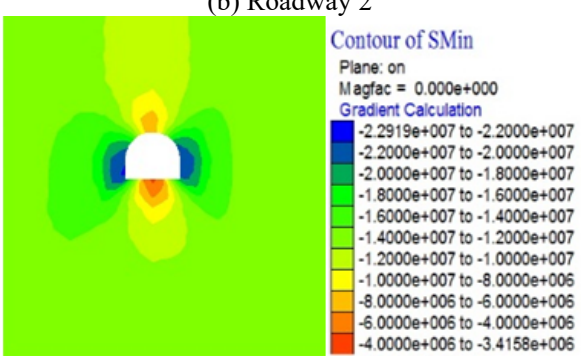

(c) Roadway 3

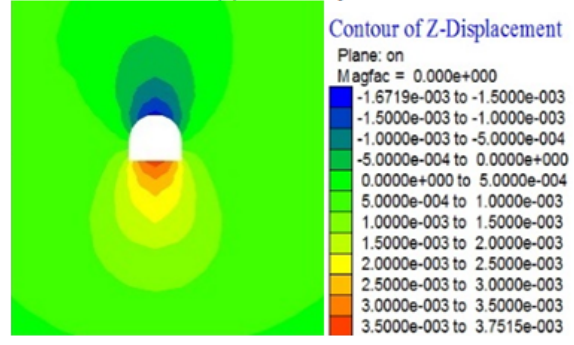

(d) Roadway 1

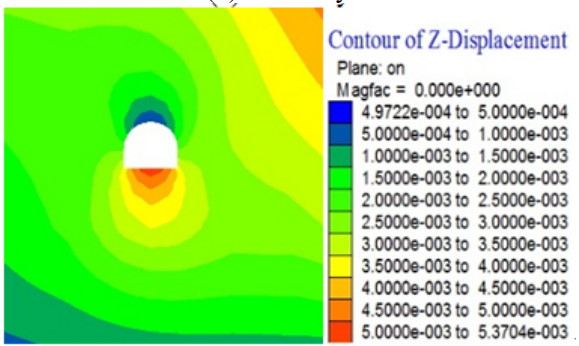

(e) Roadway 2

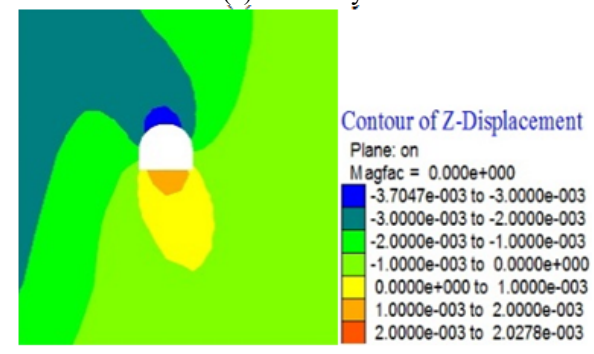

(f) Roadway 3

Fig. 12. Cloud diagrams of surrounding rocks in roadways before mining

The maximum principal stress, plastic failure, and displacement field of surrounding rocks in roadways before mining of the working face are basically similar to those of the model without fault based on the fault trend simulation. Roadway 1 is far from the fault zone, and the concentrated stress on the two sides of the roadway is basically consistent with that without fault. In Roadway 2, the concentrated stress on the two sides is significantly different from that in the model without fault. The maximum concentrated stress decreases from the $24 \mathrm{MPa}$ to $19.8 \mathrm{MPa}$. In Roadway 3, the concentrated stress of surrounding rocks slightly declines to $23 \mathrm{MPa}$. This finding reflects that before the extraction of the working face, different reactions occur at different positions of the roadway during the early excavation, which are caused by the existence of the fault zone. The displacement field is significantly different from that without the existence of fault. The displacement in Roadway 1 is basically similar to that without the existence of faults, whereas the displacements in Roadways 2 and 3 are significantly different. The heaving floor volume in Roadway 2 increases from $3.5 \mathrm{~mm}$ to $5 \mathrm{~mm}$. The heaving floor volume in Roadway 3 decreases from $3.5 \mathrm{~mm}$ to $2 \mathrm{~mm}$, whereas the top displacement increases from $1.6 \mathrm{~mm}$ to 3.7 $\mathrm{mm}$. These findings indicate that the existence of fault increases the heaving floor volume at the left rise and causes the roof settlement on the right side.

The cloud diagram of maximum principal stress when the working face is advanced by $170 \mathrm{~m}$ is shown in Fig. 13 .

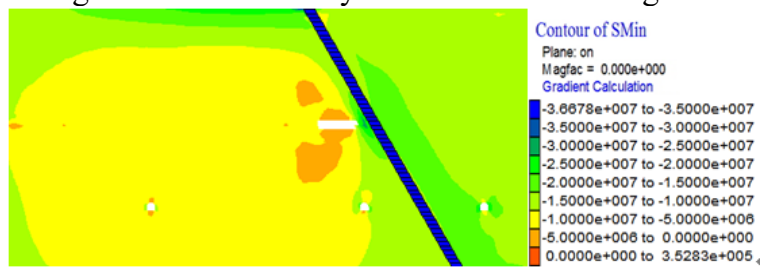

Fig.13. Cloud diagram of maximum principal stress during the extraction of the working face along the fault trend

The leading stress concentration zone on the working face runs through the fault zone during excavation along the fault trend on the basis of the overall evolution characteristics of stresses, thereby transferring the concentrated stress to the hanging wall and footwall. The enlarged views of the three roadways are shown in Fig. 14.

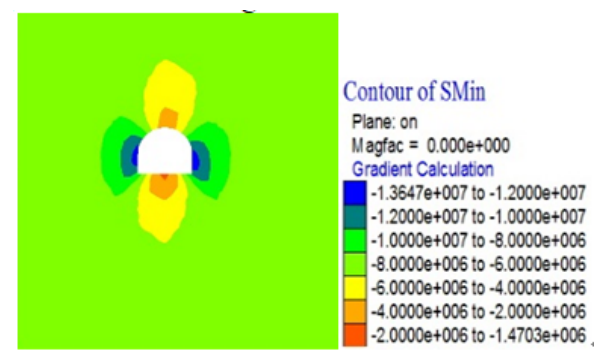

(a) Roadway 1 


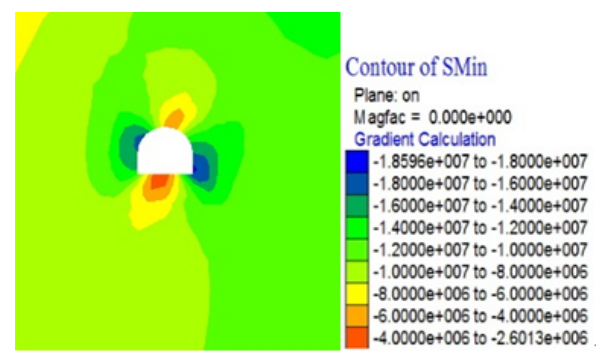

(b) Roadway 2

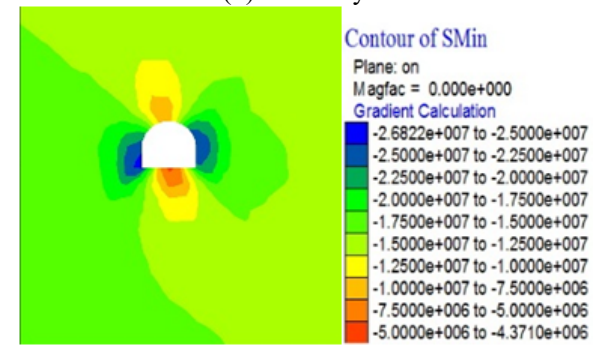

(c) Roadway 3

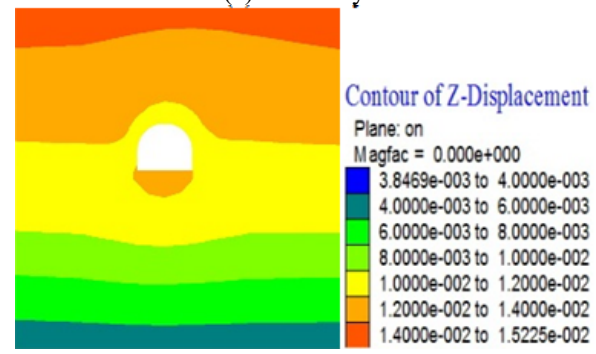

(d) Roadway 1

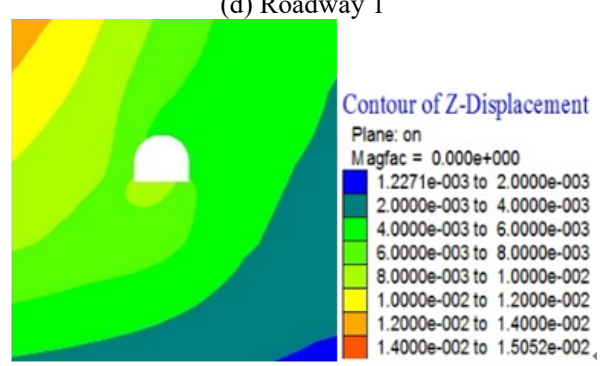

(e) Roadway 2

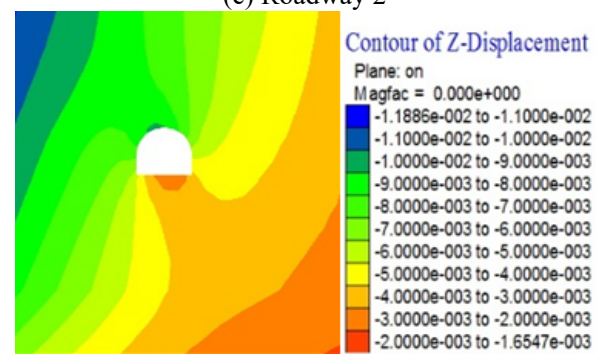

(f) Roadway 3

Fig. 14. Cloud diagram of surrounding rocks in roadways at the advancing distance of $170 \mathrm{~m}$ along the fault trend

The mining characteristics of roadways significantly change because of the extraction of the working face. The concentrated stress on the two sides of the first roadway decreases by approximately $13 \mathrm{MPa}$, and the maximum concentrated stress at the two sides of the second roadway is 18.5 MPa because of the pressure relief at the floor. The stress close to the one side of the fault zone is relatively high, and the concentrated stress on the two sides of Roadway 3 increases to $26.8 \mathrm{MPa}$. Similarly, this condition is manifested by the high degree of stress concentration on the side close to the fault zone. Compared with the simulation results of the structure without fault, the existence of fault zone produces significant differences in mining-induced stress on the surrounding rocks at the two sides of roadways close to the fault zone. Therefore, the stress concentration on the left roadway of the fault decreases, whereas that on the right roadway of the fault increases. This finding conforms to the results of similar simulation analysis.

As shown in the displacement field of surrounding rocks in roadways, the displacement of surrounding rocks in Roadway 1 is positive and ranges from $1.2 \mathrm{~cm}$ to $1.4 \mathrm{~cm}$. This finding agrees with the results of the model without fault. The displacement of surrounding rocks in Roadway 2 is also positive, and the maximum heaving floor volume ranges from $8 \mathrm{~mm}$ to $1 \mathrm{~cm}$. The displacement above the right side of Roadway 2 in the model without fault is negative whereas it is positive at the bottom accompanied with the growth of heaving floor volume. The displacement in Roadway 3 is negative. The displacement distribution in Roadway 3 in the model without fault is similar to that before the mining of the working face, indicating that the surrounding rocks in the right roadway experience an inclined squeezing pressure from the fault. The existence of fault leads to different transfer laws of mining-induced stress in the surrounding rocks of roadways.

\section{Conclusions}

The stress, displacement, and fracture fields of roadways under stepwise recovery and the controlling effects of boundary-containing fault were investigated using a similar material model to determine the controlling effects of the stope fault. The results were verified through numerical simulation. The conclusions of this study are summarized as follows:

1) Faults can significantly control the transfer of mininginduced stress at the floor of mines. During advancing along the fault trend, the mining-induced stress is close to the stress of primary rocks near the fault. It runs through the fault and forms a secondary stress at the hanging wall and footwall, which is higher than the stress of primary rocks.

2) Faults can significantly control the changes of surrounding rock stress in floor roadways of mines. The increasing and decreasing pressure amplitudes of surrounding rock stress in the roadway near the fault are higher than those at roadways far from the fault. During advancing along the fault trend, the increasing and decreasing pressure amplitudes of surrounding rock stress in the roadway reach the maximum at the hanging wall and footwall of the fault.

3) Faults can significantly control the surrounding rock failure in the floor roadways of mines. The surrounding rock failure in roadways close to the fault is more serious than that in roadways far from the fault, and the surrounding rock failure in the hanging wall and footwall of roadways is the most serious.

The conclusions of this study provide scientific reference for the advanced control and management of floor roadway deformation under the existence of fault. This study has investigated the controlling effects of fault on surrounding rock deformation at the floor during advancing along the fault trend. Many factors, such as underground mining technique and roadway layout, should be considered. The sphere of impacts of mining along the opposite direction of the fault trend, dip angle of fault, fracture of fault on the failure of stope will be evaluated in future studies. 


\section{Acknowledgements}

This study was supported by the Foundation Project of Jiangxi Digital Land Key Laboratory, China (Grant No. DLLJ201903) and by the Natural Science Foundation of Jiangxi Province, China (Grant No. 20192BAB206044).
This is an Open Access article distributed under the terms of the Creative Commons Attribution License

\section{References}

1. Jiang, B., Huang, D., Zhu, X., Yang, F., Braatz, R. D., "Canonical variate analysis-based contributions for fault identification". Journal of Process Contro, 26, 2015, pp.17-25.

2. Yu, W. J., Wang, W. J., Wu, Z. J., "Analysis on activation laws caused by coal mining in fault foot wall and its criterion". Journal of Coal Science and Engineering, 18(2), 2012, pp.123-128.

3. Wang, Q., Ran, R., Jiang, B., "Study on failure mechanism of roadway with soft rock in deep coal mine and confined concrete support system". Engineering Failure Analysis, 81, 2017, pp.155177.

4. Wang, L., Wang, Q., Li, S. C., "Stability analysis and characteristic of seismic activity during roadway development in soft rock". Journal of Mining \& Safety Engineering, 35(1), 2018, pp.10-18.

5. Meng, Q., Han, L., Qiao, W., "Support technology for mine roadways in extreme weakly cemented strata and its application". International Journal of Mining Science and Technology, 24(2), 2014, pp. 157-164.

6. Zhao, Z., Wang, W., Wang, L., "Compression-shear strength criterion of coal-rock combination model considering interface effect", Tunneling \& Underground Space Technology Incorporating Trenchless Technology Research, 47, 2015, pp.193-199.

7. Wei, L. I, Shu L., "Model test study of surrounding rock deformation and failure mechanism of deep roadway with thick top coal". Tunneling \& Underground Space Technology, 47(10), 2015, pp.5263.

8. Li, Q., Shi, W., "Deformation mechanisms in a coal mine roadway in extremely swelling soft rock". Springerplus, 5(1), 2016, pp.1310.

9. He, F., 1., Zhang, G. C., "Analysis and control of stability of the fractured soft rock surrounding a deep roadway". Rock and Soil Mechanics, 36(5), 2015, pp.1397-1406.

10. Wang, X. Y., Bai, J. B., Wang, M., "Study on asymmetric instability mechanism and control technology for roadway in deep inclined rock strata with weak plane". Journal of Mining \& Safety Engineering, 32(4), 2015, pp.544-551.

11. Yuan, L., Xue, J. H., Liu, Q. S., "Surrounding rock stability control theory and support technique in deep rock roadway for coal mine". Journal of China Coal Society, 36(4), 2011, pp.535-543.

12. Guo, P., He, M., Wang, J., "Study on coupling support technique in the roadway of Hecaogou No. 2 Coal Mine with soft roadway of large deformation". Geotechnical and Geological Engineering, 36(2), 2017, pp.1-13.

13. Li, Z., Wang, E., Ou, J., "Hazard evaluation of coal and gas outbursts in a coal-mine roadway based on logistic regression model". International Journal of Rock Mechanics \& Mining Sciences, 80, 2015, pp.185-195.

14. Yang, Y., Wei, S., Zhang, D., "Influence of rock burst and other disasters on stability of surrounding rock of roadway". Geotechnical and Geological Engineering, 36(3), 2018, pp.17671777.

15. Wang, H., Xue, S., Jiang, Y., "Field investigation of a roof fall accident and large roadway deformation under geologically complex conditions in an underground coal mine". Rock Mechanics and Rock Engineering, 51(6), 2018, pp.1863-1883.

16. Lian, Z. S., Wang, J. R., Hao, C. Y., "Numerical simulation and experimental research of surrounding rock deformation of floor roadway under short-distance coal seam group combined mining". Journal of Coal Science and Engineering, 16(3), 2010, pp.230-234.

17. Liang, D., Guang, Z., Xiao, L., "Similar simulation device for unloading effect of deep roadway excavation and its application". Journal of Mountain Science, 15(5), 2018, pp.1115-1128.

18. Dou, Z. S., Wu, J. W., Wang, L., Zhai, X. R., Li, W. Q., "Similar physical simulation on the deformation of surrounding rocks of floor roadway caused by coal mining under tectonic stress". Journal of Engineering Science and Technology Review, 10(2), 2017, pp.132-140.

19. Islam, M. R., Shinjo, R., "Mining-induced fault reactivation associated with the main conveyor belt roadway and safety of the Barapukuria Coal Mine in Bangladesh". International Journal of Coal Geology, 79(4), 2009, pp.115-130.

20. Wang, X. Y., Bai, J. B., Li, L., "Study on deformation and failure mechanism and control technology of mining roadway near fault". Journal of Mining and Safety Engineering, 31(5), 2014, pp.674-680.

21. Piotr, M., Lukasz, Q., Piotr, B., "The impact of the low throw fault on the stability of roadways in a hard coal mine." Studia Geotechnica et Mechanica. 39(1), 2017, pp.63-72.

22. Lu, H. F., Sheng, D., Yao, D. X., Hu, Y. B., “Analytical solution of critical water inrush pressure in floor mining under the influence of faults". Journal of Mining and Safety Engineering, 31(6), 2014. pp.888-895.

23. Xu, Q., W., Zhu, H. H., "Model test and numerical simulation of progressive failure of surrounding rock of cross-fault tunnel". Journal of Rock Mechanics and Engineering, 35(3), 2016, pp.433445.

24. Ding, Y. Z., Ma, D., "Study on large deformation characteristics and control measures of soft rock tunnel in fault zone with high geostress". China Civil Engineering Journal, 7, 2017, pp.129-134.

25. Wang, L. P., Li, X. H., Cheng, J. L., Li, Y. B., "Roadway instability under stress concentration near the fault end and its control technique". Journal of Mining and Safety Engineering, 34(3), 2017, pp.472-478.

26. Dai, J., Jiang J. Q. "Effect of mining sequence of upper and lower wall on mining stress of fault pillar". Journal of Mining and Safety Engineering, 33(1), 2016, pp.35-41.

27. Zhai, X. R., Wu, J. W., Shen, S. H., Han, Y., "Similar material simulation study on mining stress characteristics of rock mass at fault zone boundary". Science and Technology of Safety Production in China, (5), 2014, pp.56-61.

28. Liu, B., Liu, L.B., Qi, J. Q., Song, Z. P., “Application of FBG technology in monitoring liquefaction of adjacent soil layer affected by diaphragm wall excavation". Low carbon world, (12), 2017, pp.173-174. 